\title{
Adaptive NK cell reconstitution is associated with better clinical outcomes
}

\author{
Frank Cichocki, ${ }^{1}$ Emily Taras, ${ }^{1}$ Flavia Chiuppesi, ${ }^{2}$ John E. Wagner, ${ }^{3}$ Bruce R. Blazar, ${ }^{3}$ \\ Claudio Brunstein, ${ }^{1}$ Xianghua Luo, ${ }^{4,5}$ Don J. Diamond, ${ }^{2}$ Sarah Cooley, ${ }^{1}$ Daniel J. Weisdorf, ${ }^{1}$ \\ and Jeffrey S. Miller ${ }^{1}$ \\ 'Department of Medicine, University of Minnesota, Minneapolis, Minnesota, USA. ${ }^{2}$ Department of Experimental \\ Therapeutics, Beckman Research Institute of City of Hope, Duarte, California, USA. ${ }^{3}$ Department of Pediatrics, ${ }^{4}$ Division of \\ Biostatistics, School of Public Health, and ${ }^{5}$ Masonic Cancer Center, University of Minnesota, Minneapolis, Minnesota, USA.
}

Conflict of interest: JSM serves on the Scientific Advisory Board (SAB), consults for GT BioPharma and Fate Therapeutics, and has received research funds from these relationships. He also serves on the SAB for CytoSen and Onkimmune. F. Cichocki consults for Fate Therapeutics and has received research funds from these relationships. BRB declares a financial conflict with Tmunity and Kadmon Corp and receives research funds from Fate Therapeutics. He also serves on the SAB for GT Biopharma, Magenta Therapeutic, and Five Prime Therapeutics and consults for Regeneron and Equillium Inc. DJD is the Chair of the $S A B$ of Helocyte Inc., from which he receives royalties and research funding via a sponsored research agreement. None of these relationships had a role in funding this research. All conflicts are managed per institutional policies.

License: Copyright 2019, American Society for Clinical Investigation.

Submitted: October 15, 2018 Accepted: December 18, 2018 Published: January 24, 2019

\section{Reference information:}

JCI Insight. 2019;4(2):e125553.

https://doi.org/10.1172/jici.

insight.125553.
BACKCROUND. Human cytomegalovirus (CMV) reactivation is a common occurrence early after transplant and is associated with heterogeneous NK cell subset expansion. These adaptive NK cell expansions are highly variable between recipients, with respect to magnitude and relative frequencies of adaptive NK cell subsets.

METHODS. To gain insight into the factors that influence adaptive NK cell expansion from a CMV naive graft source, we performed a high-resolution NK cell and $\mathrm{CD8}^{+} \mathrm{T}$ cell phenotypic analysis of 215 patients with hematological malignancies that were transplanted with 2 partially HLA matched CMV negative umbilical cord blood units.

RESULTS. We found that adaptive NK cells were significantly higher in recipients who received nonmyeloablative conditioning (NMAC) relative to myeloablative conditioning (MAC), and high CMV neutralizing antibody titers correlated with the degree of adaptive NK cell expansion. The frequencies of adaptive NK cell subsets (defined by NKG2C, Fc\&R $\gamma$, EAT-2, and SYK expression) that reconstitute from donor hematopoietic progenitor cells largely matched the frequencies observed in the NK cell compartment of the recipient prior to conditioning, suggesting that host - as well as viral reactivation factors - may determine the phenotypic diversification after transplant. Additionally, multivariable analyses show that higher adaptive NK cell expansion associated with better disease-free survival.

CONCLUSIONS. Our findings provide important insights into adaptive NK cell reconstitution after transplant and support a role for adaptive NK cells in promoting better clinical outcomes.

FUNDING. The NIH and the National Marrow Donor Program.

\section{Introduction}

NK cells are innate immune effectors that recognize and eliminate virally infected or malignant cells. They are the predominant population of reconstituting donor lymphocytes early after hematopoietic cell transplant (HCT) and are associated with enhanced graft-versus-leukemia $(\mathrm{GvL})$ effects independently of $\mathrm{T}$ cell-mediated graft-versus-host disease (GvHD) (1). Multiple studies have shown that rapid and robust NK cell recovery early after HCT is associated with less relapse, GvHD, nonrelapse mortality, and improved survival $(2,3)$. Given the antitumor effects of NK cells in the transplant setting, there is continued interest in understanding the factors that influence NK cell reconstitution and effector functions after transplant.

Our group has previously shown that human cytomegalovirus (CMV) reactivation, which generally occurs within the first 100 days after transplant, is associated with subsequent expansion of NK cells expressing the activating receptor NKG2C. These $\mathrm{NKG}_{2} \mathrm{C}^{+} \mathrm{NK}$ cells preferentially acquire the maturation marker CD57, are enriched for the expression of educating killer immunoglobulin-like receptors (KIR), and are primed for IFN- $\gamma$ production (4). As they are thought to be analogous to $\mathrm{Ly} 49 \mathrm{H}^{+} \mathrm{NK}$ cells that expand during mouse $\mathrm{CMV}$ infection, $\mathrm{NKG}_{2} \mathrm{C}^{+} \mathrm{NK}$ cells are referred to as adaptive. It has previously been shown that recognition of the virally encoded protein $\mathrm{m} 157$ by the activating NK cell receptor Ly49H in the mouse drives this expansion $(5,6)$, and $\mathrm{Ly} 49 \mathrm{H}^{+}$cells persist for several months even after resolution of 
the viral infection. Furthermore, $\mathrm{Ly}_{49 \mathrm{H}^{+}}$cells exhibit enhanced effector function in response to secondary viral challenges. Because Ly $49 \mathrm{H}^{+} \mathrm{NK}$ cells share traits associated with memory $\mathrm{T}$ cells (viral specificity, expansion, retraction, persistence, and recall responses), they have also been termed memory NK cells (7).

These observations have led to the hypothesis that NK cells with memory or memory-like properties may have enhanced antitumor activity, supported by recent studies demonstrating an association between CMV reactivation and reduced relapse risk after HCT (8-17). However, this finding remains controversial $(18,19)$. The discrepancies between these studies could be related to differences in treatment protocols, including the use of antithymocyte globulin (ATG), graft sources, and treatment of CMV reactivation. For example, at least 2 studies of transplant outcomes after HCT reported that CMV reactivation was associated with a decreasing cumulative incidence of relapse and better overall survival only in patients who did not receive ATG as part of their GvHD prophylaxis $(14,20)$. Another study showed that CMV reactivation was strongly associated with lower relapse in HCT patients who received delayed ganciclovir treatment compared with those who received early prophylaxis treatment (13). In our previous study, we analyzed absolute $\mathrm{CD} 56^{\mathrm{dim}} \mathrm{CD} 57^{+} \mathrm{NKG} 2 \mathrm{C}^{+} \mathrm{NK}$ cell counts at 6 months after transplant and found that recipients in the expanding group based on $\mathrm{CD} 56^{\mathrm{dim}} \mathrm{CD} 57^{+} \mathrm{NKG} 2 \mathrm{C}^{+}$ NK cell numbers $(>2.5$ cells $/ \mu 1$ blood $)$ led to a lower 2 -year relapse rate $(P=0.06)$ compared with the nonexpanding group $(0.1-2.5$ cells $/ \mu$ blood) (11). This is consistent with a recent report showing that mouse CMV specific memory NK cells exhibit enhanced effector function and augmented antitumor activity in vivo when compared with cytokine-activated NK cells (21).

We have previously shown that adaptive NK cell subsets expressing NKG2C and/or lacking FceR $\gamma$, EAT-2, and SYK arise in HCT recipients after CMV reactivation $(4,22)$, but many questions about this phenomenon remain. For example, CMV reactivation occurs during the first 100 days after transplant, but significant frequencies of adaptive NK cells are not apparent in the peripheral blood of most recipients until at least 6 months and increase in frequency out to 2 years after transplant $(4,11)$. The factors that account for the reconstitution kinetics of adaptive NK cells in response to CMV infection are unknown. Furthermore, our previous work and that of others has demonstrated significant heterogeneity in the adaptive NK cell phenotype among infected individuals $(22,23)$. Whether these phenotypes are hard wired and dictated by the genetics of the NK cells themselves or whether host factors drive the phenotypic pattern of adaptive NK cell reconstitution has yet to be determined. In the present study, we performed a high-resolution $\mathrm{NK}$ cell and $\mathrm{CD}^{+} \mathrm{T}$ cell phenotypic analysis of 215 patients with hematological malignancies that received CMV naive double umbilical cord blood (UCB) transplants, and we stratified data based on transplant conditioning regimen and recipient CMV serostatus.

\section{Results}

Adaptive NK cell reconstitution from cord blood progenitors is strongly influenced by the transplant preparative regimen. Over the past decade, the use of less-intensive therapies has dramatically increased, as hematopoietic malignancies are more likely in older patients (24). Several groups have compared immune reconstitution in myeloablative conditioning (MAC) versus non-MAC (NMAC) recipients and have reported only minor differences in T cell, B cell, NK cell, or DC reconstitution (25-28). However, most of these studies have used broad lineage-defining markers and total IgG levels. We hypothesized that there may be differences in immune reconstitution after MAC and NMAC. To this end, we validated 2 FACS panels to analyze cytotoxic lymphocyte subsets in the peripheral blood of a large cohort of double UCB transplant recipients with various hematological malignancies. The first panel included fluorescently labeled antibodies against CD3, CD56, CD57, NKG2C, EAT-2, FceR $\gamma$, and SYK and was designed to capture the heterogeneous phenotypes of adaptive NK cells induced by CMV. The second panel included fluorescently labeled antibodies against $\mathrm{CD} 3, \mathrm{CD} 4, \mathrm{CD} 8 \alpha, \mathrm{CD} 45 \mathrm{RA}, \mathrm{CD} 27$, and CCR7 and was designed to capture naive $\left(\mathrm{CCR} 7^{+} \mathrm{CD} 27^{+}\right)$, early memory $\left(\mathrm{CCR} 7^{-} \mathrm{CD} 27^{+}\right.$), and effector memory (CCR7-CD27-) $\mathrm{CD}^{+} \mathrm{T}$ cell subsets (29).

The analysis was restricted to 215 recipients (Supplemental Table 1; supplemental material available online with this article; https://doi.org/10.1172/jci.insight.125553DS1) of double UCB grafts (30), as they are CMV naive, thus providing an optimal setting to look at adaptive NK cell reconstitution in the context of the recipient CMV environment without confounding effects of donor CMV exposure. There were no significant differences in the frequencies of total CD3-CD56 ${ }^{\mathrm{dim}} \mathrm{NK}$ cells between MAC and NMAC recipients, nor were there differences when comparing CMV seronegative recipients, CMV seropositive recipients who did not reactivate virus, and CMV seropositive recipients who experienced viral reactivation 
(Supplemental Figure 1A). However, when comparing $\mathrm{CD}^{-} \mathrm{CD}^{-\mathrm{dim}} \mathrm{CD}^{\mathrm{A}} 7^{+} \mathrm{NKG} 2 \mathrm{C}^{+}$, as well as $\mathrm{CD} 3^{-} \mathrm{CD}$ $56^{\mathrm{dim}} \mathrm{CD} 57^{+} \mathrm{Fc} E \mathrm{R} \gamma^{-}$and $\mathrm{CD} 3^{-} \mathrm{CD} 56^{\mathrm{dim}} \mathrm{CD} 57^{+} \mathrm{EAT}-2^{-}$adaptive NK cell subsets, there were markedly higher frequencies in NMAC relative to MAC recipients. Frequencies of adaptive NK cells were significantly higher in the recipient 1 year after transplant in NMAC recipients who experienced CMV reactivation. Furthermore, the association between $\mathrm{CD} 3{ }^{-} \mathrm{CD} 56^{\mathrm{dim}} \mathrm{CD} 57^{+} \mathrm{NKG} 2 \mathrm{C}^{+}$adaptive $\mathrm{NK}$ cell expansion and CMV infection was stronger than that observed for other adaptive NK cell markers (FcER $\gamma^{-}$and EAT-2-) (Figure 1) (Supplemental Figure 2). The gating strategy used to identify adaptive NK cell subsets is shown in Supplemental Figure 3A. Similar results were observed when comparing absolute numbers of NK cells (Supplemental Figure 4). Additionally, we observed a suppressive effect of acute GvHD on CD3-CD56 ${ }^{\mathrm{dim}} \mathrm{C}$ $\mathrm{D}^{5} 7^{+} \mathrm{NKG} 2 \mathrm{C}^{+}$adaptive NK cell expansion in both MAC and NMAC recipients, though frequencies were still greater in NMAC relative to MAC recipients when stratified by acute GvHD (Supplemental Figure 5).

When comparing $\mathrm{CD}^{+}{ }^{+} \mathrm{CD} 4^{-} \mathrm{CD}^{+} \mathrm{T}$ cell frequencies in recipients stratified by $\mathrm{CMV}$, there were no differences between the MAC and NMAC groups. However, $\mathrm{CD} 3^{+} \mathrm{CD} 4^{-} \mathrm{CD} 8^{+} \mathrm{T}$ cell expansion was higher in CMV seropositive recipients and recipients in whom CMV was reactivated relative to CMV seronegative recipients (Supplemental Figure 1B). In contrast to adaptive NK cells, no differences were seen in naive, early memory, or effector memory $\mathrm{CD} 8^{+} \mathrm{T}$ cell subsets when grouped by transplant conditioning. Trends toward lower frequencies of naive $\mathrm{CD}^{+} \mathrm{T}$ cells and higher frequencies and absolute numbers of effector memory $\mathrm{CD}^{+} \mathrm{T}$ cells in recipients in whom reactivated CMV were seen (Figure 2) (Supplemental Figure 6). The gating strategy used to identify $\mathrm{CD} 8^{+} \mathrm{T}$ cell subsets is shown in Supplemental Figure 3B. Similar results were observed when comparing absolute numbers of $\mathrm{T}$ cells (Supplemental Figure 7). These findings are consistent with previous reports showing that the vast majority of $\mathrm{CMV}$-reactive $\mathrm{CD} 8^{+} \mathrm{T}$ cells have a CD27- phenotype $(31,32)$. Of note, the overall rates of CMV reactivation in double UCB transplant recipients were similar between MAC (50\% [95\% CI, 42\%-58\%]) and NMAC (50\% [95\% CI, 43\%-57\%] recipients through day 100 after transplant $(P=0.58)$. As expected, the vast majority of reactivation events occurred before day 100, as the rate of reactivation increased only slightly in both MAC (52\% [95\% CI, $44 \%-60 \%$ ] and NMAC (54\% [95\% CI, 47\%-61\%] recipients out to 1 year after transplant. Together, our data show that, among cytotoxic lymphocyte subsets, pretransplant conditioning uniquely affects adaptive NK cell reconstitution.

CMV neutralizing antibody titers are significantly higher in NMAC compared with MAC recipients 1 year after transplant, and adaptive NK cell frequencies correlate with CMV neutralizing antibody titers. Given that CMV reactivation is an event that occurs within the first 100 days after HCT, we were curious as to why the expansion of adaptive NK cells appeared to be such a late event (between 6 months and 2 years after transplant) (Figure 1 and Supplemental Figure 4). One potential explanation for late reconstitution kinetics is that adaptive NK cell expansion could be dependent, at least in part, on the presence of anti-CMV antibodies. Multiple groups have reported that in vitro expansion and function of adaptive NK cells cocultured with autologous monocytes or macrophages is markedly enhanced in the presence of plasma or serum from CMV seropositive (but not CMV seronegative) donors, possibly through amplified CD16 signaling $(22,23,33,34)$. However, in vivo support for this finding is lacking.

To test the hypothesis that CMV-specific antibodies are associated with the expansion of adaptive NK cells, we first analyzed $\mathrm{CD} 19^{+} \mathrm{B}$ cell frequencies and absolute numbers in peripheral blood samples from our transplant cohort. Overall, B cell frequencies and absolute numbers were low early after transplant and increased between 6 months and 1 year. Our data are consistent with a previous analysis showing that robust B cell reconstitution does not occur until 9-12 months after HCT (27). No differences in frequencies or absolute numbers were observed between the MAC and NMAC groups for CMV seronegative recipients and CMV seropositive recipients who did not reactivate virus. Lower frequencies of $\mathrm{CD} 19^{+} \mathrm{B}$ cells were observed in the NMAC relative to the MAC group for CMV seropositive recipients who reactivated virus. Interestingly, the frequencies and absolute numbers of $\mathrm{CD} 19^{+} \mathrm{B}$ cells was significantly lower at the 6 month and 1 year after transplant time points for recipients in whom CMV was reactivated relative to the CMV seronegative and nonreactivation groups (Supplemental Figure 8).

While total peripheral blood B cell numbers between MAC and NMAC recipients were similar, we hypothesized that differences in CMV-specific antibody titers could still exist. To test this hypothesis, we assayed plasma or serum samples from 212 transplant recipients for CMV neutralizing antibody (NAb) titers. As expected, CMV NAb titers (NT) were at or below the limit of detection at all time points analyzed in CMV seronegative recipients (Figure 3A). In contrast, CMV NT remained low in CMV seropositive recipients who 
CD57 ${ }^{+} \mathrm{NKG}^{-} \mathrm{C}^{+} \mathrm{NK}$ cells $\mathrm{CMV}$ reactivation

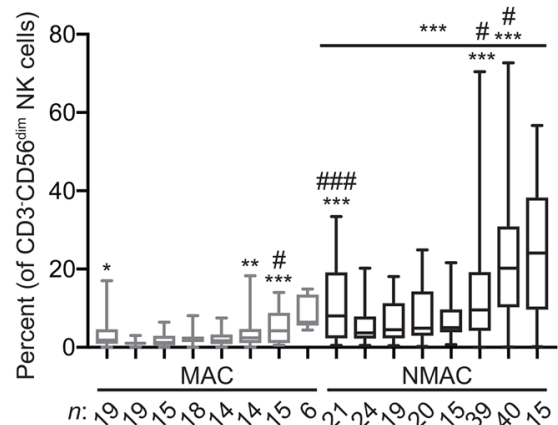

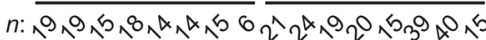

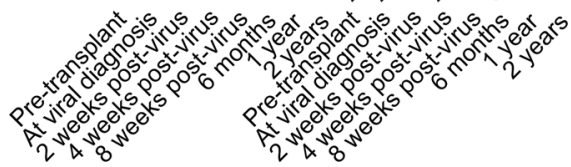

CD57+FceR ${ }^{-}$NK cells

$\mathrm{CMV}$ reactivation
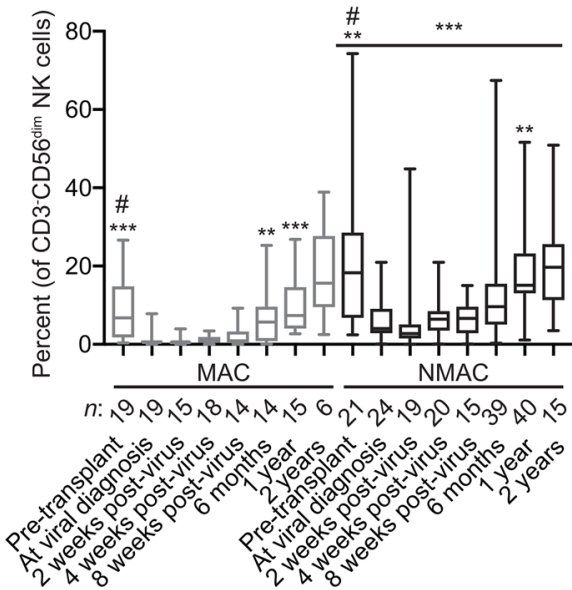

CD57'EAT-2' NK cells CMV reactivation

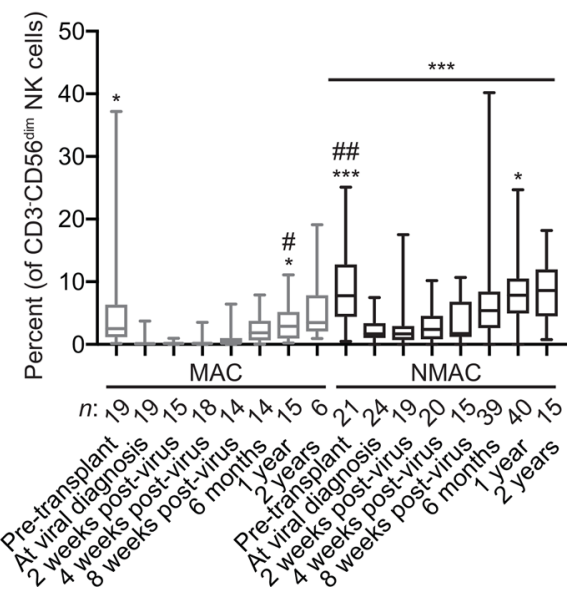

Figure 1. High-resolution analysis of adaptive NK cell reconstitution from umbilical cord blood progenitors in HCT recipients. Three hundred thirteen peripheral blood samples drawn from pre- or posttransplant HCT recipients in whom CMV was reactivated were analyzed by FACS to determine the per-

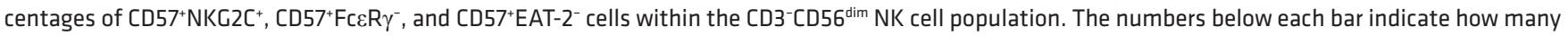
individual transplant samples constitute each group. Solid lines with statistics above the NMAC columns in each graph indicate 2-way ANOVA analyses of the MAC versus NMAC groups. The ${ }^{*}$ symbols above individual columns indicate statistically significant differences between average values at those time points compared with matched time points from CMV seronegative HCT recipients calculated using unpaired $t$ tests. The \# symbols above individual columns indicate statistically significant differences between average values at those time points compared with matched time points from HCT recipients who were CMV seropositive without viral reactivation calculated using unpaired $t$ tests. ${ }^{*} P<0.05,{ }^{* *} P<0.01,{ }^{* * *} P<0.001,{ }^{\#} P<0.05$, ${ }^{\# \#} P<0.01,{ }^{\# \#} P<$ 0.001. Box and whisker plots show means, along with minimum and maximum values.

experienced viral reactivation through the first 6 months after transplant, followed by a significant spike in titers later beyond 1 year, but only in recipients who received NMAC with their transplant (Figure 3B).

To determine whether adaptive NK cell frequencies directly correlated with CMV NT, we plotted $\mathrm{CD}^{-}{ }^{-} \mathrm{CD} 56^{\mathrm{dim}} \mathrm{CD} 57^{+} \mathrm{NKG} 2 \mathrm{C}^{+}, \mathrm{CD}^{-} \mathrm{CD} 56^{\mathrm{dim}} \mathrm{CD} 57^{+} \mathrm{F} c \varepsilon \mathrm{R} \gamma^{-}$, and $\mathrm{CD} 3^{-} \mathrm{CD} 56^{\mathrm{dim}} \mathrm{CD} 57^{+} \mathrm{EAT}-2^{-}$adaptive NK cell absolute numbers against CMV NAb titer values. For NMAC, but not MAC HCT recipients, CMV NT positively correlated with adaptive NK cell counts. This was most evident for adaptive NK cells with the $\mathrm{CD} 3{ }^{-} \mathrm{CD} 56^{\mathrm{dim}} \mathrm{CD} 57^{+} \mathrm{NKG} 2 \mathrm{C}^{+}$phenotype (Figure $4 \mathrm{~A}$ ). The association between $\mathrm{CMV}$ $\mathrm{NAb}$ titer and adaptive NK cell absolute numbers was also observed when restricting the analysis to only the 1-year posttransplant time point (Supplemental Figure 9). However, this association was not apparent when naive, early memory, and effector memory CD8 ${ }^{+} \mathrm{T}$ cell frequencies were plotted against CMV NT (Figure 4B). Together, our data demonstrate that pretransplant conditioning profoundly influences CMV NAb production by reconstituted B cells after CMV reactivation. Moreover, adaptive NK cell absolute numbers correlate with CMV NT, providing in vivo evidence for an association between CMV-specific antibodies and adaptive NK cell expansion.

The phenotypic patterns of adaptive NK cells that arise in response to CMV may be determined by the host environment. The study of immune reconstitution in the cord blood transplant setting provides a unique opportunity to compare host factors for NK cell differentiation from recipient-derived progenitors before transplant and differentiation of NK cells from donor-derived, CMV seronegative progenitors after transplant. We hypothesized that such an analysis could be informative in determining which factors strongly influence the phenotypic heterogeneity of adaptive NK cells. If the frequencies of distinct adaptive subsets were similar in reconstituting donor NK cells after HCT compared with recipient NK cells before transplant, it would suggest that the host environment plays a predominant role in driving the pattern of adaptive NK cell heterogeneity. If, on the other hand, the frequencies of distinct adaptive NK cell subsets were divergent between reconstituting donor NK cells after HCT and recipient NK cells before transplant, it would suggest that heterogeneity is intrinsic to the NK cells and is largely influenced by the genetics of the NK cells themselves.

To differentiate between these possibilities, we plotted frequencies of adaptive NK cells expressing NKG2C or lacking FceR $\gamma$, EAT-2, or SYK before and after transplant for individual CMV seropositive recipients who experienced viral reactivation. Based on the findings in Figure 1, we focused only on recipients 
$\mathrm{CCR} 7^{+} \mathrm{CD} 27^{+}$naive $\mathrm{T}$ cells CMV reactivation
CCR7-CD $27^{+}$early memory $T$ cells $\mathrm{CMV}$ reactivation
CCR7 $-\mathrm{CD} 27^{-}$effector memory $\mathrm{T}$ cells $\mathrm{CMV}$ reactivation
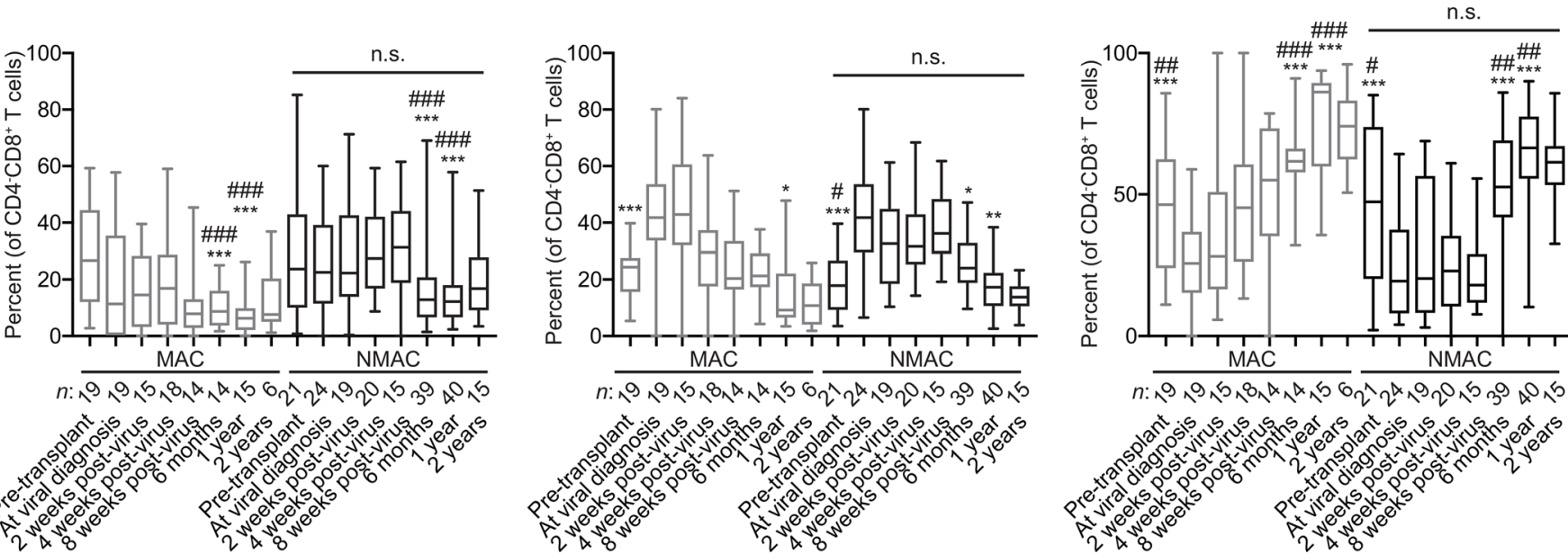

Figure 2. High-resolution analysis of $\mathrm{CD8}^{+} \mathrm{T}$ cell reconstitution from umbilical cord blood progenitors in HCT recipients. Three hundred thirteen peripheral blood samples drawn from pre- or posttransplant HCT recipients in whom CMV was reactivated were analyzed by FACS to determine the percentages of $\mathrm{CCR7} 7^{+} \mathrm{CD} 27^{+}$naive cells, CCR7-CD27+ early memory cells, and CCR7-CD27- late memory cells within the total CD3 $3^{+} \mathrm{CD} 4^{-} \mathrm{CD} 8^{+} \mathrm{T}$ cell population. The numbers below each bar indicate how many individual transplant samples constitute each group. Solid lines with statistics above the NMAC columns in each graph indicate 2-way ANOVA analyses of the MAC versus NMAC groups. The ${ }^{*}$ symbols above individual columns indicate statistically significant differences between average values at those time points compared with matched time points from CMV seronegative HCT recipients calculated using unpaired $t$ tests. The \# symbols above individual columns indicate statistically significant differences between average values at those time points compared with matched time points from HCT recipients who were CMV seropositive without viral reactivation calculated using unpaired $t$ tests. ${ }^{*} P<0.05$, ${ }^{* *} P<0.01$, ${ }^{* * *} P<0.001,{ }^{\#} P<0.05,{ }^{\# \#} P<0.01,{ }^{\# \#} P<0.001$. Box and whisker plots show means, along with minimum and maximum values.

who received NMAC with their transplant for the remaining analyses. We found that recipients exhibiting low $(<5 \%)$ adaptive NK cell frequencies before transplant also exhibited low adaptive NK cell frequencies within reconstituting donor NK cells, despite viral reactivation (Figure 5A). Conversely, we observed that, in general, high frequencies of adaptive NK cell subsets expressing NKG2C or lacking FceR $\gamma$, EAT-2, or SYK in recipient NK cells pretransplant were associated with high frequencies of these subsets within reconstituting donor NK cells after viral reactivation (Figure 5B and Supplemental Figure 10). To test the significance of this association, we compared cumulative (transplants 1-18) pretransplant and 1 year posttransplant adaptive NK cell frequencies in recipients grouped by low $(<5 \%)$ and high $(<5 \%)$ frequencies pretransplant. Importantly, no significant differences in adaptive NK cell frequencies were observed when comparing the pre- and 1-year posttransplant samples within the low or high groups. The exception was adaptive $\mathrm{CD} 57^{+} \mathrm{NKG} 2 \mathrm{C}^{+}$cells, which were observed at a higher frequency 1 year after transplant in the high group (Figure $5 \mathrm{C}$ ).

To examine the pattern of adaptive NK cell reconstitution further, we also gated on $\mathrm{CD} 3^{-} \mathrm{CD} 56^{\mathrm{dim}} \mathrm{C}$ $\mathrm{D}^{2} 7^{+} \mathrm{NKG} 2 \mathrm{C}^{+}$recipient $\mathrm{NK}$ cells before transplant and $\mathrm{CD} 3{ }^{-} \mathrm{CD} 56^{\mathrm{dim}} \mathrm{CD} 57^{+} \mathrm{NKG} 2 \mathrm{C}^{+}$donor $\mathrm{NK}$ cells at 1 year and 2 years after transplant in CMV seropositive recipients who reactivated virus. Within the $\mathrm{CD} 56^{\mathrm{dim}} \mathrm{CD} 57^{+} \mathrm{NKG} 2 \mathrm{C}^{+}$subset for each sample, we analyzed the percentages of EAT-2-, FceR $\gamma^{-}$, and $\mathrm{SYK}^{-}$cells. Overall, we observed similar frequencies of EAT-2-, FceR $\gamma^{-}$, and $\mathrm{SYK}^{-}$cells in donor $\mathrm{CD}_{56}{ }^{\mathrm{dim}} \mathrm{CD} 57^{+} \mathrm{NKG} 2 \mathrm{C}^{+} \mathrm{NK}$ cells at 1 and 2 years after transplant compared with recipient $\mathrm{CD} 56^{\mathrm{dim}} \mathrm{C}_{-}$ D57 ${ }^{+} \mathrm{NKG} 2 \mathrm{C}^{+} \mathrm{NK}$ cells before transplant (Figure 6). Determination of HLA variant expression based on partial donor/recipient mismatch confirmed that both canonical and adaptive NK cell subsets were completely donor derived at all time points after CMV reactivation (Supplemental Figure 11). Together, our data support the hypothesis that different patterns of adaptive NK cell diversification are driven primarily by the virus and the host environment.

Adaptive NK cell frequencies after HCT are stable over time. Previous studies of patients with genetic mutations have provided evidence for enhanced persistence/survival of adaptive NK cells relative to canonical NK cells $(35,36)$. We were interested in whether adaptive NK cells that arise in HCT recipients in response to $\mathrm{CMV}$ reactivation also exhibit long-term persistence. To address this question, we again looked at NK cells from individual NMAC transplant recipients in whom CMV was reactivated before day 100 after transplant. 
A

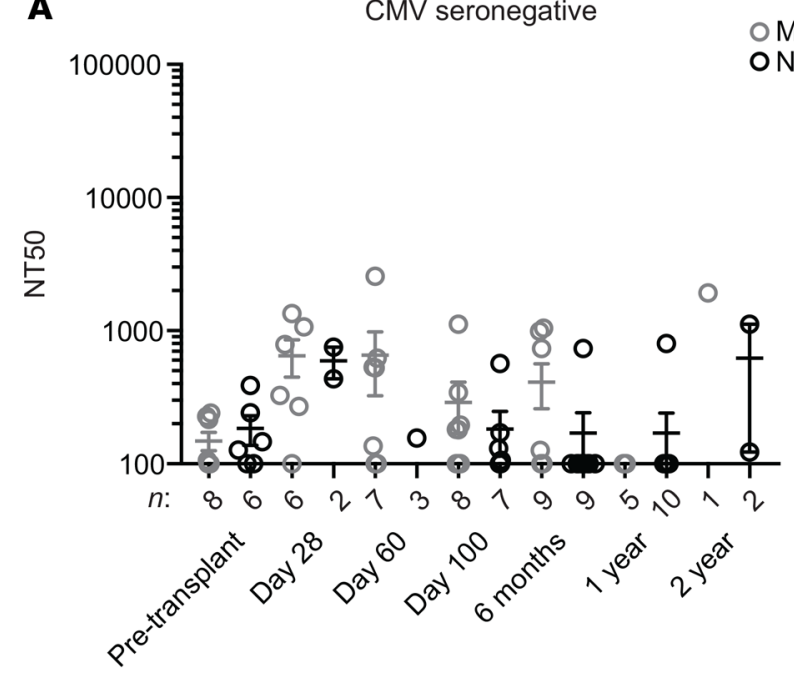

B

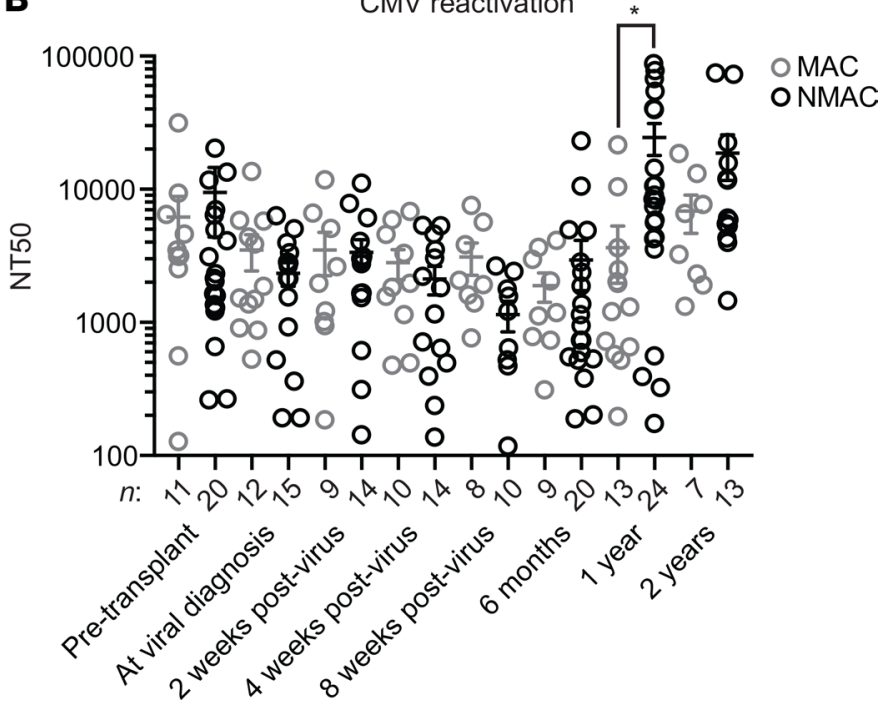

Figure 3. Analysis of CMV neutralizing antibody titers in HCT recipients. (A) Eighty-three serum or plasma samples from CMV seronegative transplant recipients before or after transplant and (B) 219 serum or plasma samples from transplant recipients who experienced CMV reactivation were analyzed to measure neutralizing CMV antibody titers (NT50). Values from MAC samples are represented by gray circles, and those from NMAC samples are shown in black. Statistical significance between MAC and NMAC samples was determined using unpaired $t$ tests. ${ }^{*} P<0.05$. Box and whisker plots show means, along with minimum and maximum values.

We analyzed donor-derived $\mathrm{CD} 3^{-} \mathrm{CD} 56^{\mathrm{dim}} \mathrm{CD} 57^{+} \mathrm{NKG} 2 \mathrm{C}^{+}$adaptive $\mathrm{NK}$ cells at 6 months, 1 year, and 2 years after transplant and looked at the relative percentages of Fc\&R $\gamma^{+} \mathrm{EAT}-2^{+}, \mathrm{Fc \varepsilon R} \gamma-\mathrm{EAT}-2^{+}$, Fc\&R $\gamma^{+} \mathrm{EAT}-2^{-}$, and $\mathrm{Fc \varepsilon R} \gamma^{-} \mathrm{EAT}-2^{-}$cells within the $\mathrm{CD} 56^{\mathrm{dim}} \mathrm{CD} 57^{+} \mathrm{NKG} 2 \mathrm{C}^{+}$adaptive $\mathrm{NK}$ cell subset over time (Figure 7A). Similarly, we also analyzed donor-derived $\mathrm{CD} 3^{-} \mathrm{CD} 56^{\mathrm{dim}} \mathrm{CD} 57^{+} \mathrm{F} c \varepsilon \mathrm{R} \gamma^{-}$adaptive NK cells at the same time points after transplant and looked at the relative percentages of NKG2C-EAT-2 $2^{+}$NKG2 $\mathrm{C}^{+} \mathrm{EAT}-2^{+}$, NKG2C-EAT-2-, and NKG2C ${ }^{+}$EAT-2- cells within the CD3-CD56 ${ }^{\mathrm{dim}} \mathrm{CD} 57^{+} \mathrm{F} \mathrm{C} \varepsilon \mathrm{R} \gamma^{-}$adaptive NK cell subset over time (Figure 7B). Using these gating schemes, stable patterns of adaptive NK cell subsets were seen. Of note, there were some recipients (transplants 10, 6, and 24) where the $\mathrm{Fc \varepsilon R} \gamma^{-}$subpopulation expanded over time (Figure 7A). While we cannot rule out the possibility that adaptive NK cells turn over rapidly, and new cells differentiating from progenitors acquire very similar phenotypic patterns, our results support the long-term persistence of adaptive NK cells.

Better disease-free survival explained by lower relapse and treatment-related mortality in NMAC transplant recipients with high adaptive NK cell counts at 6 months after HCT. We previously reported results from a study of 674 HCT recipients who received matched sibling or UCB grafts. We found that CMV reactivation was associated with lower leukemia relapse and superior disease-free survival (DFS) in NMAC but not MAC transplant recipients. Furthermore, using recursive partitioning, we found that $\mathrm{CD} 3{ }^{-} \mathrm{CD} 56^{\mathrm{dim}} \mathrm{CD} 57^{+} \mathrm{NKG} 2 \mathrm{C}^{+}$ NK cell counts higher than 2.5 cell/ $\mu$ l blood at 6 months were associated with lower 2-year relapse rates (11). To extend these findings using the phenotypic data generated in the present study, we performed multivariate analyses for DFS between 6 months and 2 years after transplant using adaptive NK cell numbers at the 6-month time point. We also performed analyses of time-varying differences in cumulative incidence of relapse and treatment-related mortality (TRM). Adaptive NK cell numbers were dichotomized into upper ( $\geq 33$ th percentile) and middle/low ( $<67$ th percentile) groups for this analysis. Supplemental Table 2 shows the transplant variables for these clinical analyses. Consistent with our previous results, we observed better DFS, lower relapse, and lower TRM in recipients with higher numbers of $\mathrm{CD} 3^{-} \mathrm{CD} 56^{\mathrm{dim}} \mathrm{CD} 57^{+} \mathrm{NK}-$ $\mathrm{G}^{2} \mathrm{C}^{+}$NK cells (Figure 8A) and $\mathrm{CD} 3{ }^{-} \mathrm{CD} 56^{\mathrm{dim}} \mathrm{CD} 57^{+} \mathrm{Fc} \varepsilon \mathrm{R} \gamma-\mathrm{NK}$ cells (not shown). While these findings were consistent, they did not reach statistical significance for adaptive NK cells using this definition. Similar trends were observed for absolute numbers of $\mathrm{CD} 3^{-} \mathrm{CD} 56^{\mathrm{dim}} \mathrm{CD} 57^{+} \mathrm{EAT}-2^{-} \mathrm{NK}$ cells. In contrast, comparisons between the upper and middle/low percentile groups for $\mathrm{CD} 3{ }^{-} \mathrm{CD} 56^{\mathrm{dim}} \mathrm{CD} 57^{+} \mathrm{EAT}-2^{-} \mathrm{NK}$ cells showed statistically significant improvements in DFS for the highest tertile of adaptive NK cells $(P=$ 0.05 ), as well as significantly lower overall and later risks of relapse (median 1.45 versus 0.67 years) after transplant $(P \leq 0.05)$ (Figure $8 \mathrm{~B})$, suggesting that this subset has the strongest predictive value for these 
A
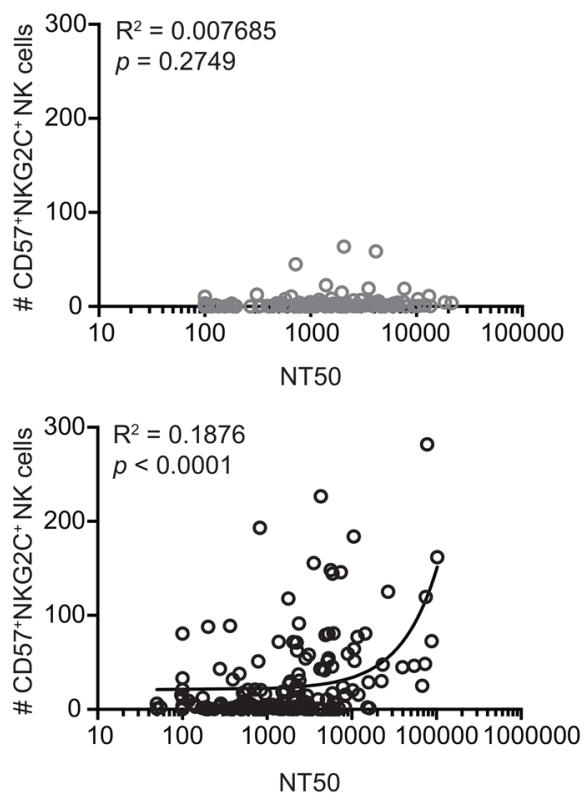

B
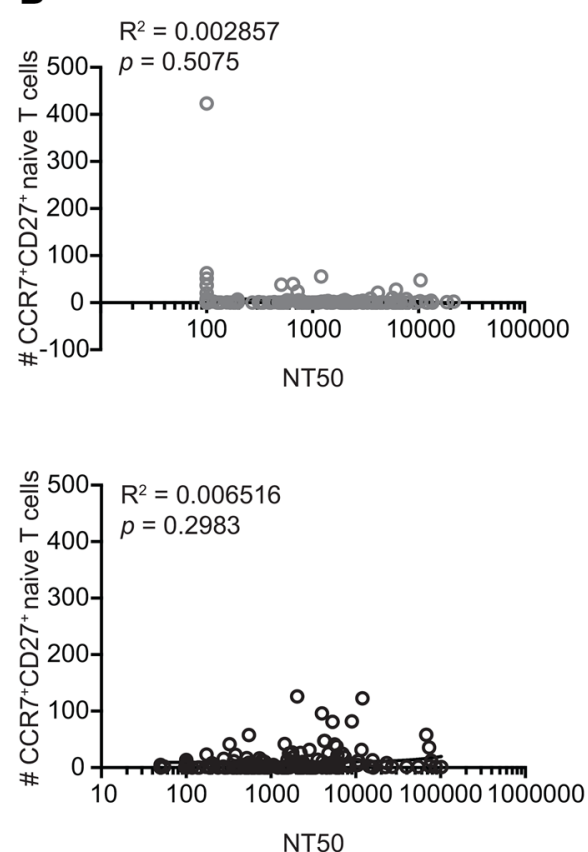
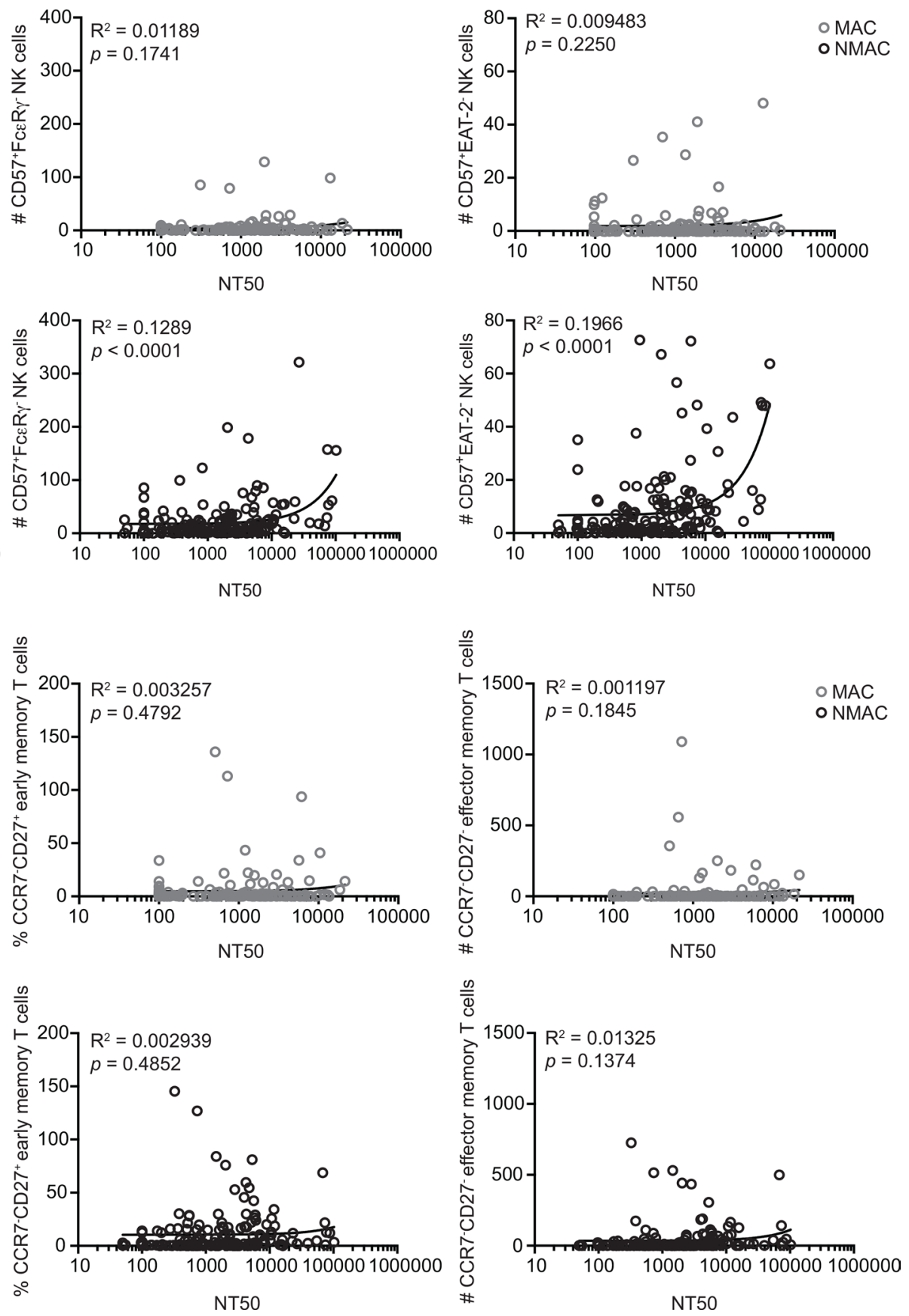

Figure 4. Correlations between adaptive NK cell and CD8+ $\mathbf{T}$ cell frequencies and CMV neutralizing antibody titers in HCT recipients. (A and B) Scatter plots of NT50 values assayed from plasma or serum against matching adaptive NK cell frequencies (A) and CD8 $8^{+}$cell subset frequencies (B) found in peripheral blood from 302 unique transplant samples. Data from MAC recipients are shown in gray, and data from NMAC recipients are shown in black.

important clinical outcomes. Multivariate regression tables corresponding to these analyses are shown in Supplemental Table 3.

\section{Discussion}

Here, we performed a detailed analysis of adaptive NK cell reconstitution in a cohort of 215 double UCB transplant recipients, a CMV naive graft source. We found that adaptive NK cell reconstitution was strongly influenced by the pretransplant preparative regimen, with considerably more robust reconstitution in recipients who received reduced intensity conditioning. Our analysis of plasma and serum samples showed 

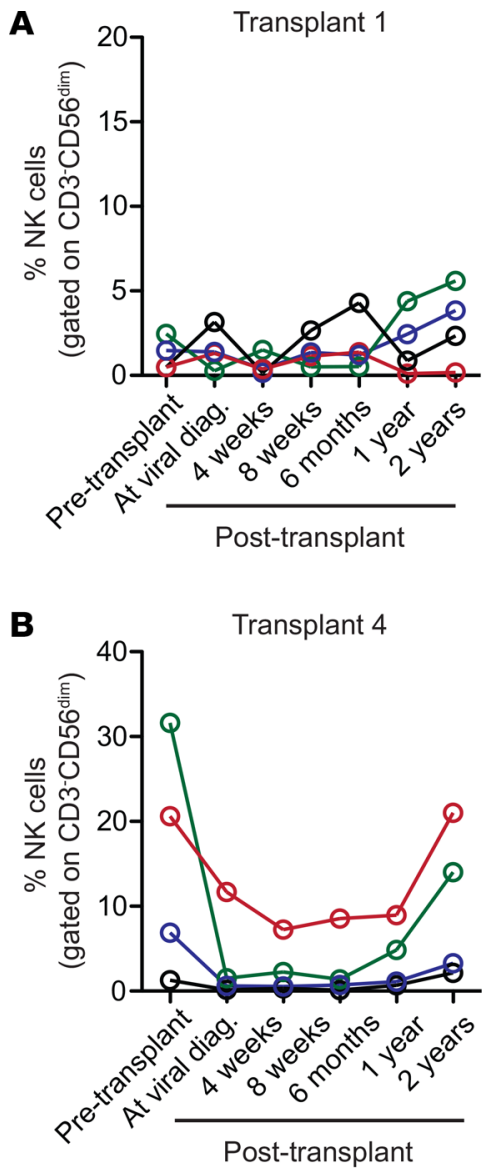

Post-transplant

$\%$ Recipient pre-transplant $\%$ Donor post-transplant

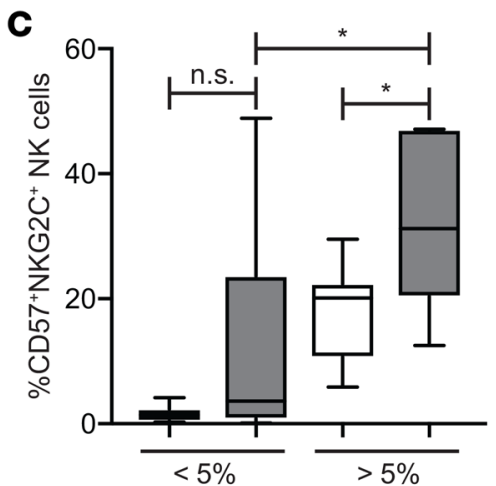

pre-transplant pre-transplant

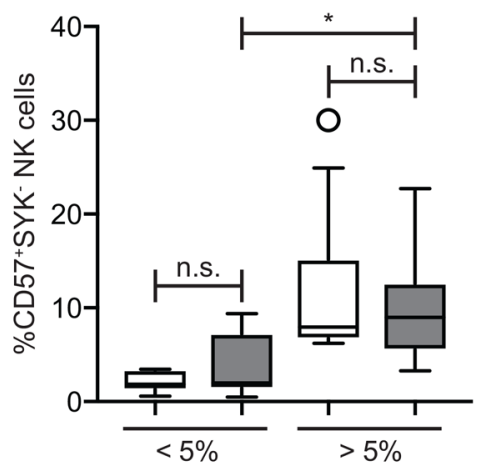

pre-transplant pre-transplant
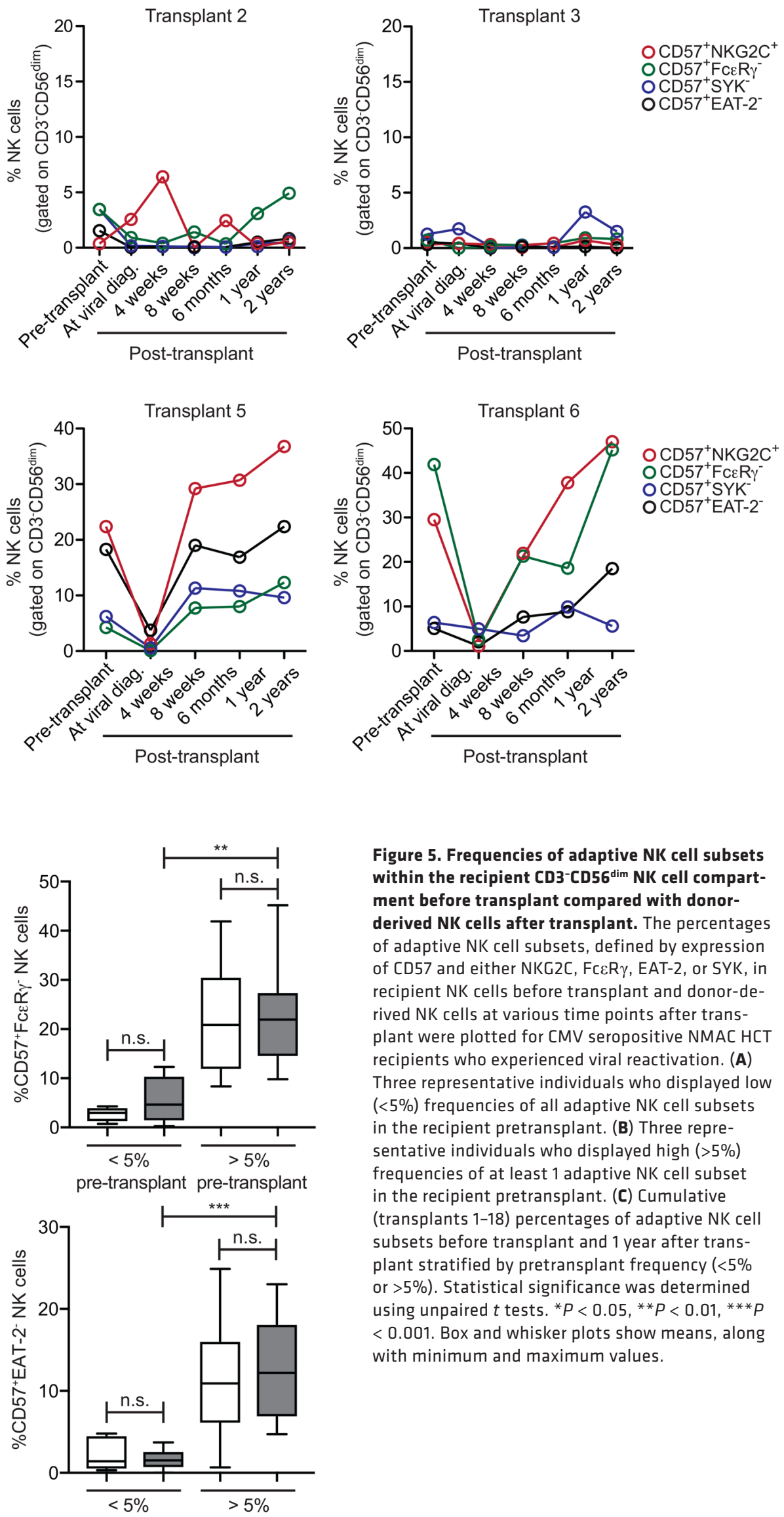

pre-transplant pre-transplant

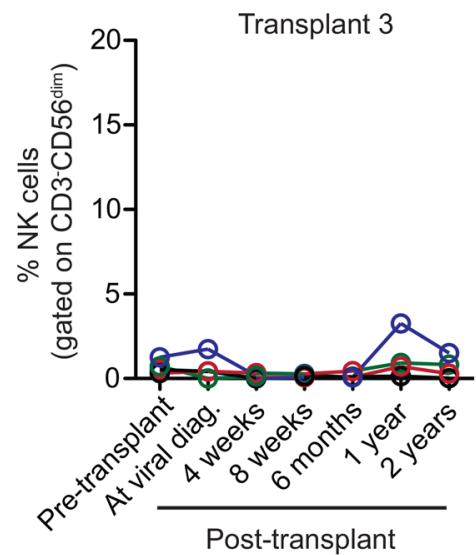

O CD $57^{+} \mathrm{NKG} 2 \mathrm{C}$ CD57 $7^{+} \mathrm{FCER} \gamma$ O CD $57^{+}$SYK CD $57^{+}$EAT-2 

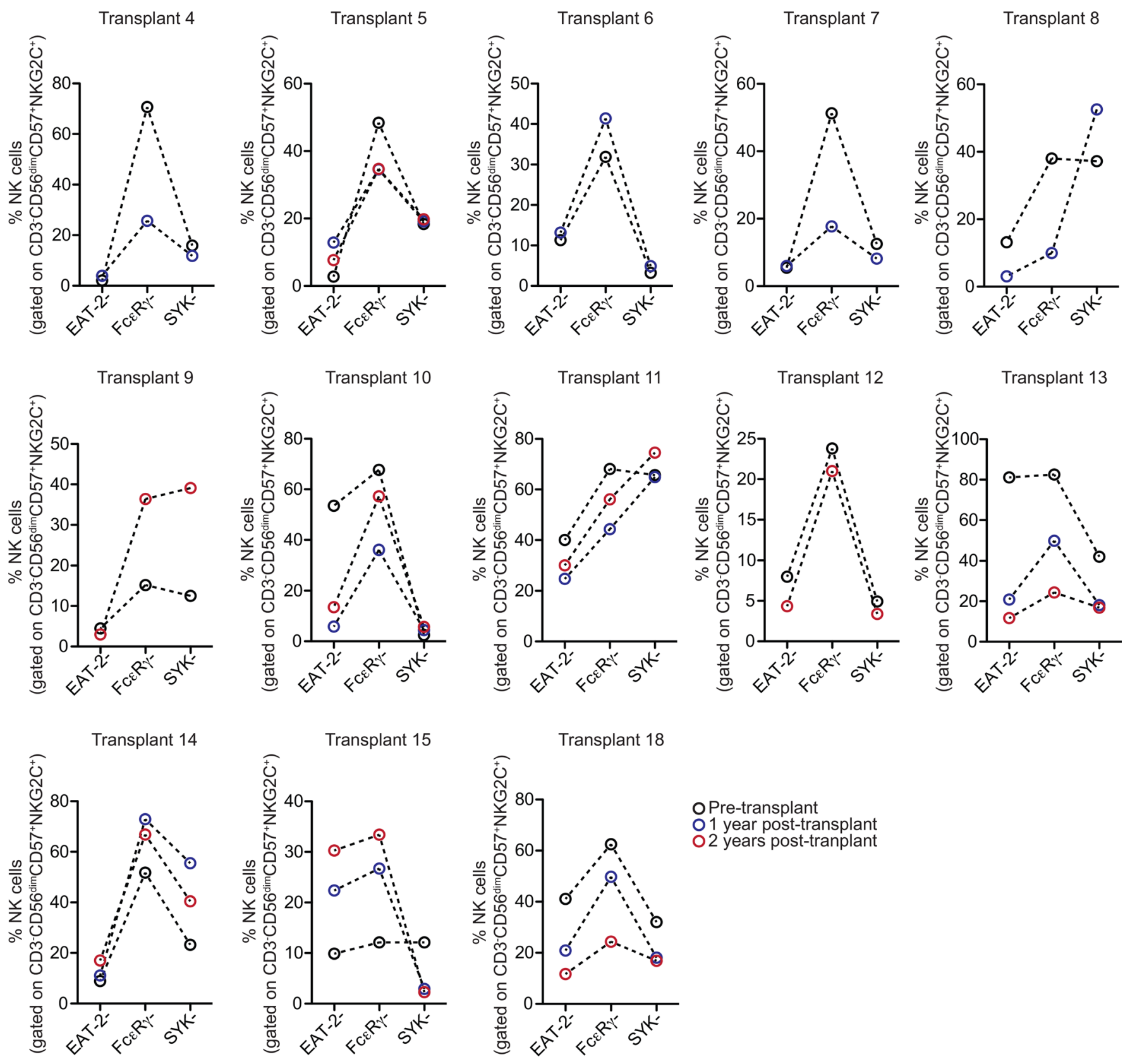

OPre-transplant

O 1 year post-transplant

O2 years post-tranplant

Figure 6. Frequencies of EAT-2-, FceR $\gamma^{-}$, and SYK- cells within the CD3-CD56 dim CD57+NKG2C+ ${ }^{+}$KK cell subset in recipient NK cells before transplant and donorderived NK cells after transplant. The percentages of EAT-2- Fc\&R $\gamma^{-}$, and SYK- cells within the CD3-CD56 ${ }^{\text {dim }}$ CD57 $7^{+} N K C 2 C^{+}$subset in NK cells from the recipient before transplant compared with donor NK cells at 1 year and 2 years after transplant. All recipients were CMV seropositive and experienced CMV reactivation.

markedly higher CMV NT at 1 and 2 years after transplant in NMAC recipients, with NAb titer levels correlating with the degree of adaptive NK cell expansion.

The reason for the association between pretransplant conditioning and CMV NT at later time points after transplant is unclear. However, there may be significant differences in the induction of long-lived plasma cells and memory B cells between MAC and NMAC recipients that could account for our observed differences in CMV NT after transplant. It is known that myeloablative conditioning causes both thymic injury (37) and a loss of $\mathrm{T}$ cell zone fibroblastic reticular cells and CCL21 expression in lymphoid stroma (38) after transplant. Additionally, a recent HSCT study in rhesus macaques reported disruption of the lymph node architecture as a result of total body irradiation (TBI). The recovery of the $\mathrm{CD} 4^{+} \mathrm{T}$ cell pool in tissues appeared to occur at a slower rate than the recovery of $\mathrm{CD}^{+} \mathrm{T}$ cells in the peripheral blood, suggesting that changes in trafficking rates between lymph nodes and peripheral blood can be affected by irradiation. Furthermore, $\mathrm{CD} 4^{+} \mathrm{T}$ cell recovery in axillary 
A

\section{CD3-CD56 ${ }^{+} \mathrm{CD} 57^{+} \mathrm{NKG}^{-} \mathrm{C}^{+} \mathrm{NK}$ cells}

6 months 1 year 2 years

Transplant 10
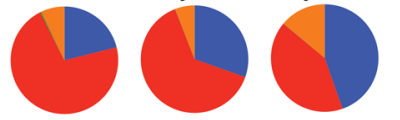

Transplant 5
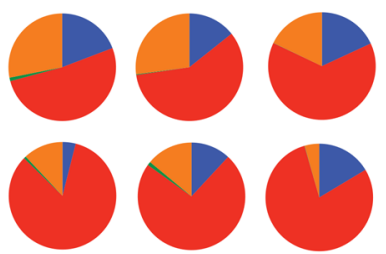

Transplant 15
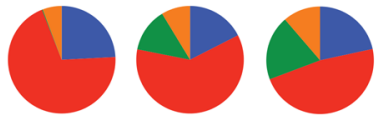

Transplant 6
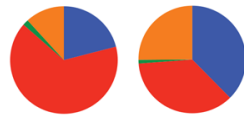

Transplant 19
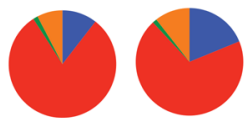

Transplant 20
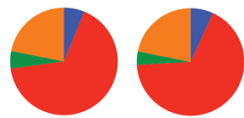

Transplant 21
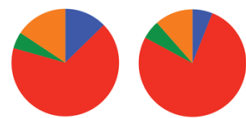

Transplant 22
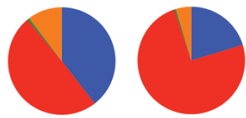

Transplant 23
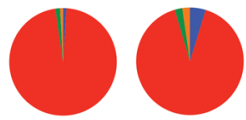

Transplant 13
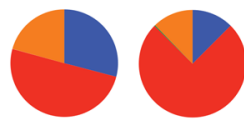

Transplant 7
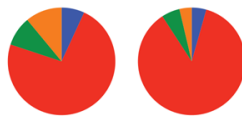

Transplant 24

Transplant 25
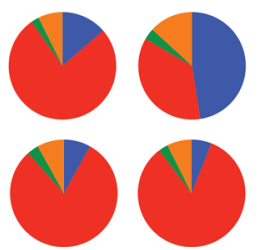

B

FC\&R $\gamma^{+}$EAT $-2^{+}$

FceR ${ }^{-}$EAT-2 $2^{+}$

FCER $\gamma^{+}$EAT-2

FCER $\gamma$-EAT-2

Transplant 10

Transplant 5

CD3-CD56 ${ }^{+} \mathrm{CD} 57^{+} \mathrm{F}$ ceR $\gamma^{-}$NK cells

6 months 1 year 2 years
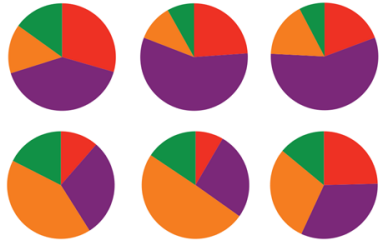

$\square$ NKG2C+EAT-2 ${ }^{+}$

$\square$ NKG2C-EAT-2-

$\square$ NKG2C ${ }^{+}$EAT-2
Transplant 26

Transplant 15

Transplant 27

Transplant 28

Transplant 29

Transplant 6

Transplant 22

Transplant 30

Transplant 31
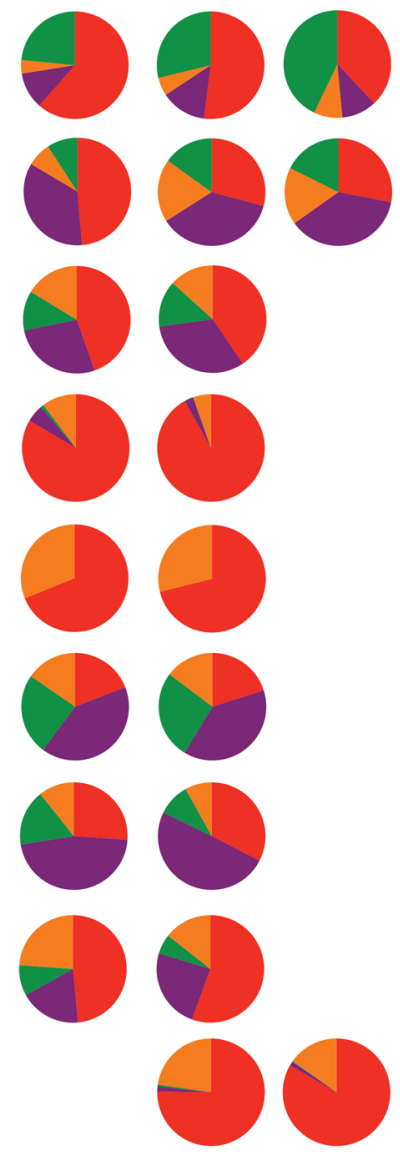

Transplant 12
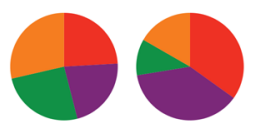

Transplant 32

Transplant 33
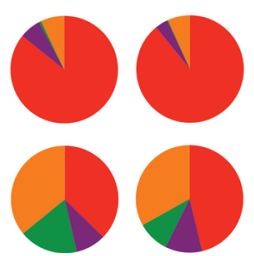

Figure 7. Comparison of adaptive NK cell phenotypic patterns in individual HCT recipients from 6 months to 2 years after transplant. Comparisons of donor-derived NK cells at 6 months, 1 year, and 2 years after transplant. Both (A) CD $3^{-}$CD56 dim CD57+NKC2C+ and (B) CD3-CD56 dim CD57+FCER $\gamma^{-}$populations were fractionated based on FceR $\gamma$ and EAT-2 or NKG2C and EAT-2 expression, respectively. Pie charts show the relative frequencies of each subset. Fourteen transplant recipients were analyzed for each population, and each row represents 1 recipient.

lymph nodes was suboptimal out to at least 1 year after transplant (39). It is, thus, possible that chemotherapy-induced damage to additional lymphoid tissue such as lymph nodes or spleen could affect $\mathrm{B}$ cell differentiation and/or function. This may be a challenging hypothesis to test in humans, given the tissue residency of these cells, but further exploration of B cell reconstitution in the context of transplant preconditioning is warranted. It is also possible that adaptive NK cells play a direct role in promoting the CMV NAb production by B cells 
A

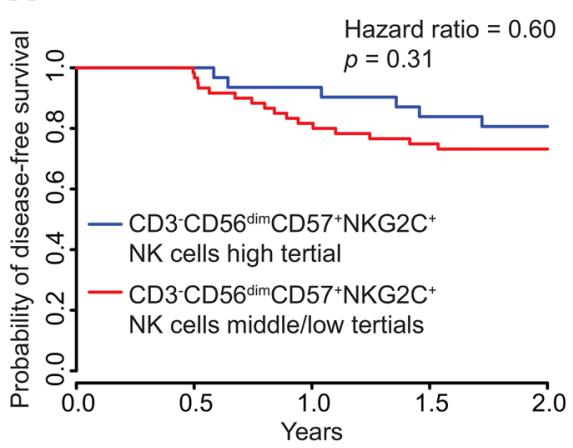

B

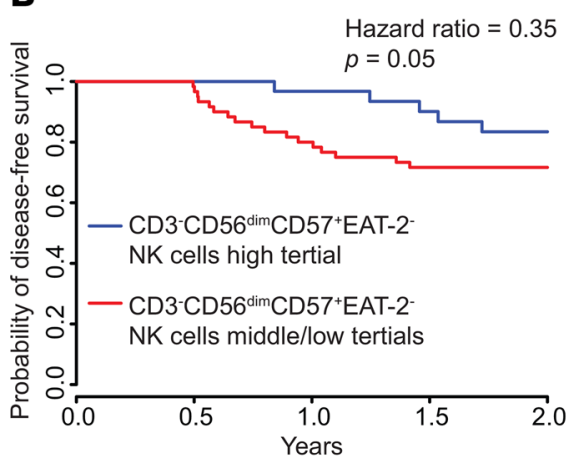

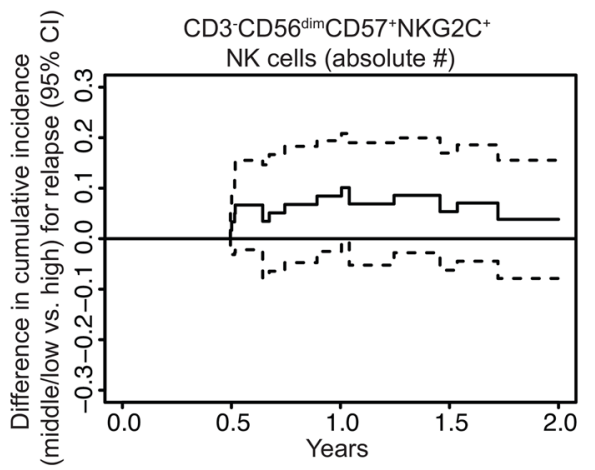
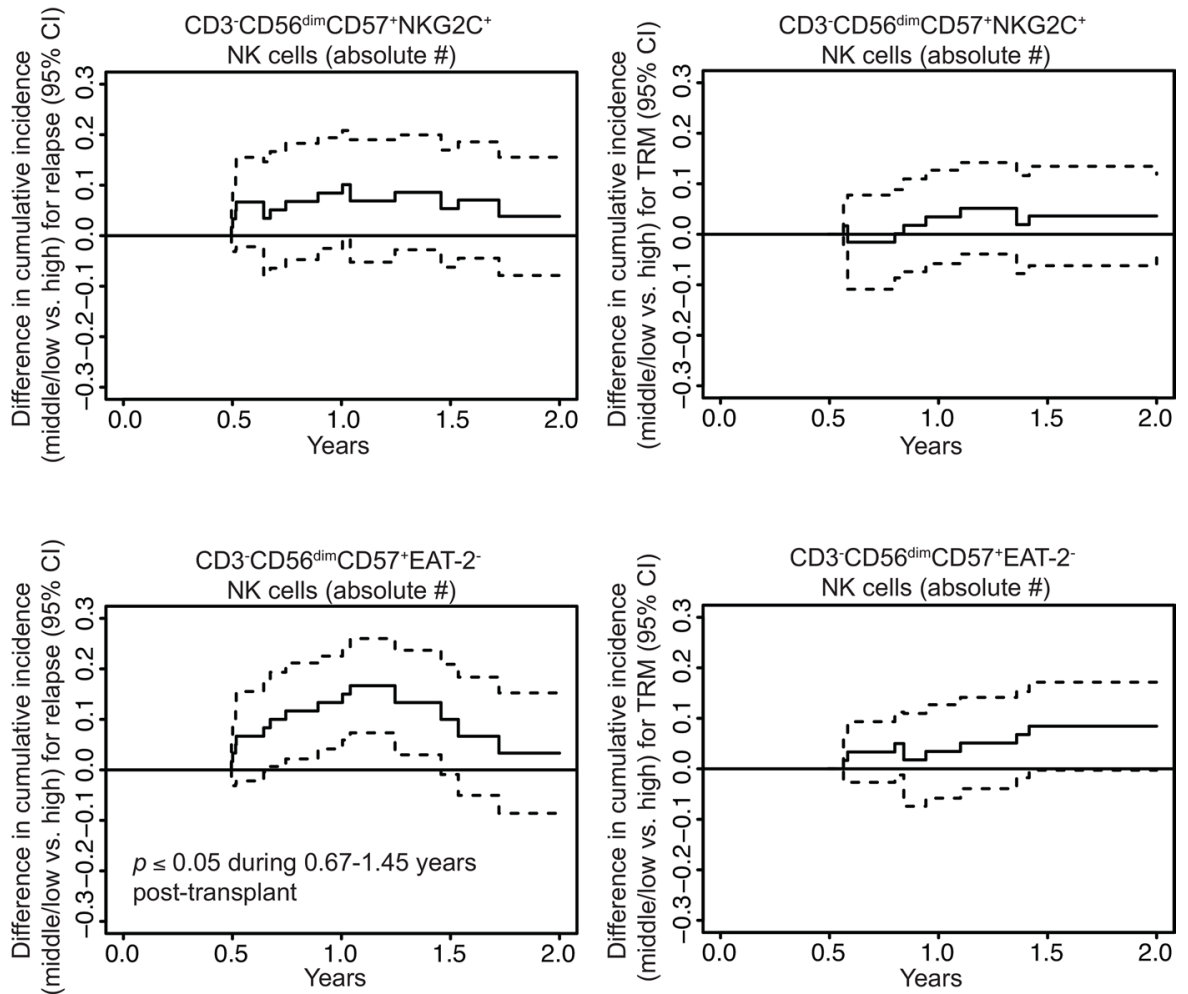

Figure 8. Multivariable analyses of DFS and time-varying cumulative incidence differences in relapse and TRM in NMAC transplant recipients dichotomized by adaptive NK cell counts at $\mathbf{6}$ months after HCT. Multivariate regressions for DFS and time-varying difference in relapse and treatment-related mortality between 6 months and 2 years after transplant were conducted for NMAC transplant recipients. Absolute numbers of (A) CD3-CD56 dim CD57+NKC2C ${ }^{+}$NK cells and (B) CD3-CD56 ${ }^{\text {dim }}$ CD57+EAT-2- NK cells were dichotomized into upper ( $\geq 67$ th percentile) and middle/low (<67th percentile) groups for analysis.

through reduced killing of autologous $\mathrm{T}$ follicular helper cells. Such a model has been proposed to explain associations between adaptive NK cells and induction of HIV NAb responses (40).

Our analysis of adaptive NK cell reconstitution in individual NMAC transplant recipients revealed that the pattern of adaptive NK cell subsets based on expression of NKG2C, Fc\&R $\gamma$, EAT-2, and SYK was similar between cells from the recipient before transplant and donor-derived cells after transplant. These patterns, once established after transplant, remained consistent over time. Therefore, our data suggest that adaptive NK cell heterogeneity in the NMAC setting is largely defined by the host environment and not intrinsic factors of the NK cells themselves. The precise mechanisms that drive the remarkable degree of adaptive NK cell heterogeneity observed among CMV-infected individuals is unclear. Recent work has demonstrated that sequence variation in CMV UL40-encoded peptides, which can be presented by the NKG2C ligand HLA-E, influence the activation and expansion of $\mathrm{NKG}_{2} \mathrm{C}^{+} \mathrm{NK}$ cells in concert with the inflammatory cytokines IL-12 and IL-18 (41). It is possible that other variations in CMV-encoded proteins also influence the expansion of adaptive NK cells lacking FceR $\gamma$, EAT-2, and SYK.

Multivariate analyses of DFS, relapse, and TRM showed that NMAC recipients with high numbers of adaptive NK cells at 6 months after HCT had better DFS, lower relapse, and lower TRM. We acknowledge that our modest cohort size limits definitive clinical conclusions about adaptive NK cells and their subsets. However, these data support the hypothesis that higher numbers of adaptive NK cells are associated with protection against relapse and warrant future analyses in larger and independent transplant cohorts to validate these findings.

In summary, our data are important because they show that while the absolute number of reconstituting NK cells is the same between MAC and NMAC allogeneic transplants, the quality and stable functional repertoire of these NK cells after CMV reactivation is very different and associates with late elevation of high-affinity CMV NT. This difference in NK cell reconstitution may explain why CMV reactivation seems to better correlate with relapse protection in the NMAC setting (11). While adaptive NK cell expansion 
is more robust in the NMAC setting, NK cells are a smaller population in MAC transplant setting where intrinsic donor genetic factors such as killer-cell Ig-like receptor-ligand (KIR-ligand) mismatch and donor KIR haplotypes are predictive of relapse protection (42). While it is clear that NK cells contribute to the GvL effect in the transplant setting, our data show that transplant conditioning significantly influences the functional NK cell repertoire, and this variable needs to be accounted for in all future analyses.

\section{Methods}

Transplant procedures. Patients eligible for MAC received fludarabine $25 \mathrm{mg} / \mathrm{m}^{2} /$ day i.v. on days $-8,-7$, and -6 ; cyclophosphamide $60 \mathrm{mg} / \mathrm{kg}$ / day i.v. on day -7 and -6 ; and TBI 165 cGy twice a day on days $-4,-3,-2$, and -1 with the infusion of MGTA-456 on day 0 (43). Patients eligible for NMAC received cyclophosphamide 50 $\mathrm{mg} / \mathrm{kg}$ /day i.v. on day -6 ; fludarabine $40 \mathrm{mg} / \mathrm{kg}$ /day on day $-6,-5,-4,-3$, and -2 ; and TBI 200 cGy once on day -1 (43). Regardless of conditioning, GvHD immunoprophylaxis consisted of cyclosporine (targeting trough levels $200-400 \mu \mathrm{g} / 1)$ on days -3 to +100 with a $10 \%$ taper per week thereafter, and mycophenolate mofetil $15 \mathrm{mg} / \mathrm{kg}$ i.v. 3 times a day on days -3 to +45 if no $\mathrm{GvHD}$ was present on day +45 .

$C M V$ screening and treatment. Prior to conditioning, all recipients were assessed for CMV exposure by serology using enzyme-linked immunosorbent assays. A CMV IgG antibody level above $10.0 \mathrm{EU} / \mathrm{ml}$ was considered seropositive. After transplant, all recipients were screened weekly for CMV reactivation either by pp65 antigenemia (prior to 2006) or quantitative PCR (qPCR) (2006 and after) until day +100 after transplant. CMV prophylaxis included high-dose acyclovir $\left(500 \mathrm{mg} / \mathrm{m}^{2}\right)$ i.v. every 8 hours or $800 \mathrm{mg}$ orally 5 times per day. CMV reactivation was defined as CMV antigenemia ( $\geq 2$ pp65-positive cells/50,000), DNA positive ( $\geq 500$ copies by qPCR), or culture of CMV from blood, body fluid, or tissue and was treated with ganciclovir or foscarnet.

Phenotypic analysis of reconstituting NK cells and T cells in HCT recipients. Peripheral blood mononuclear cells (PBMCs) from HCT recipients were isolated by density gradient centrifugation and analyzed by FACS using an LSR II flow cytometer instrument (BD Biosciences). PBMCs from recipients were collected before transplant. PBMCs from recipients in whom CMV was reactivated were collected at viral diagnosis; at 2, 4, and 8 weeks after antiviral therapy; and at 6 months, 1 year, and 2 years after transplant. For recipients who were CMV seronegative or were CMV seropositive but did not reactivate virus, PBMCs were collected at day 28, day 60, day 100, 6 months, 1 year, and 2 years after transplant. Cell surface and intracellular staining was performed as previously described (22). Briefly, frozen samples were thawed and rested overnight in RPMI media with $10 \%$ FBS (Thermo Fisher Scientific) without cytokines in a $37^{\circ} \mathrm{C}$ incubator. The following day, approximately $0.5 \times 10^{6}$ to $4 \times 10^{6}$ cells were stained for surface markers and fixable dead cell stain in FACS buffer (PBS [Thermo Fisher Scientific], 2\% BSA [Thermo Fisher Scientific], and 2 mM EDTA [MilliporeSigma]). Cells were then fixed in $2 \%$ paraformaldehyde and permeabilized with $0.05 \%$ Triton X-100 (MilliporeSigma), followed by intracellular staining. For secondary staining, fluorochrome-labeled anti-rabbit IgG (BioLegend, clone Poly4064) was used. All fluorescently conjugated antibodies used for phenotypic analysis are listed in Supplemental Table 4. Of note, SYK was only included in the staining panel for approximately one-half of the samples analyzed because of antibody availability. Flow cytometry data was analyzed using FlowJo software (v9.9.3, FlowJo).

$C M V N A b$ titer assays. ARPE-19 retinal epithelial cells were purchased from the American Type Culture Collection (ATCC) and maintained in DMEM (Corning) supplemented with $10 \%$ FBS (VWR). A version of the CMV strain TB40/E expressing GFP was derived from TB40/Ewt-GFP BAC DNA (a gift from T.A. Shenk and E.A. Murphy, Princeton University, Princeton, New Jersey, USA) (44). Viral stocks were prepared by virus propogation in ARPE-19 cells and titrated as described $(45,46)$. A standard microneutralization assay was used to determine the NT at which 50\% CMV infection was inhibited (NT50) (46). Complement inactivation in serum and plasma samples was performed prior to the assay by incubating the samples at $56^{\circ} \mathrm{C}$ for 50 minutes. Heat-inactivated immune sera were serially 2 -fold diluted, and dilutions ranged from $1: 100$ to $1: 204,800$. Diluted samples were mixed with complete growth medium containing approximately 9000 PFU of TB40/E. After 2-hour incubation, virus/sera mixtures were added in duplicate to ARPE-19 cells. Plates were incubated for 48 hours and fixed in methanol/acetone. Infected cells were immunostained using anti-CMV immediate-early 1 (IE1) antibody (p63-27) (47), provided by W. Britt (University of Alabama at Birmingham, Birmingham, Alabama, USA) and the Vectastain ABC kit (Vector Laboratories). The substrate was DAB (Vector Laboratories). A DMi8 inverted microscope (Leica) was used to capture pictures of each well. IE1-positive nuclei per field of view using a $5 \times$ objective were counted using ImagePro Premier 
(Media Cybernetics). For each dilution, the average number of positive nuclei in duplicate was calculated. The percent NT for each dilution was calculated as follows: NT $=(1-$ [positive nuclei number with immune sera]/[positive nuclei number with preimmune sera] $) \times 100$. NT50 were calculated by determining the linear slope of the graph plotting NT versus plasma dilution by using the next higher and lower NT values closest to $50 \%$ neutralization.

Statistics. Two-way ANOVA, unpaired $t$ test, and linear regression analyses were performed using GraphPad Prism (v6.0). All $t$ tests were 2-tailed, and $P$ values less than 0.05 were considered significant. For clinical endpoint analyses, nonmyeloablative conditioning patients who survived 180 days and were free of relapse were analyzed for clinical endpoints including relapse, TRM, and DFS through 2 years after HCT. Multivariable Fine-Gray regression was used for relapse and TRM, and Cox regression was used for DFS. The primary covariates of interest were adaptive NK cell absolute counts at the 6-month visit, which were dichotomized into high ( $\geq 67$ th percentile) and medium/low ( $<67$ th percentile) groups. Adjusted variables included age group $(<18,18-45$, and $\geq 45$ years old), disease group (acute lymphoblastic leukemia [ALL], acute nonlymphocytic leukemia [ANLL], chronic myeloid leukemia [CML], other leukemia, myelodysplasia, Non-Hodgkin's lymphoma, Hodgkin's lymphoma, myeloproliferative disease, and multiple myeloma), disease risk group (high and standard), and HCT-comorbidity index (high, intermediate, and low). Time-varying differences in cumulative incidence function between high and medium/low adaptive NK cell count groups were estimated for relapse and TRM (48). All clinical analyses were performed using SAS version 9.4 (SAS Institute).

Study approval. The University of Minnesota Blood and Marrow Transplant Program prospectively collected data regarding patient characteristics and outcomes. The University of Minnesota IRB approved all protocols, and all patients (and/or their legal guardians) provided informed consent in accordance with the Declaration of Helsinki. All data were deidentified prior to use in this study.

\section{Author contributions}

F. Cichocki conceptualized the study; collected, assembled, analyzed, and interpreted data; and wrote the manuscript. ET collected, assembled, and analyzed the data. F. Chiuppesi collected, assembled, analyzed, and interpreted data. JEW, BRB, and CB reviewed and edited the manuscript. XL analyzed clinical endpoint data. DJD provided reagents, interpreted data, and reviewed and edited the manuscript. SC assembled, analyzed, and interpreted data. DJW conceptualized the study and reviewed the manuscript. JSM conceptualized the study, interpreted data, and wrote the manuscript.

\section{Acknowledgments}

The authors thank the Flow Cytometry Shared Resource, Clinical Trials Office, the Translational Therapy Laboratory, and the Oncology Medical Informatics and Services at the University of Minnesota, as well as the research nurses and clinical staff for sample procurement. This work was supported by NIH R00HL123638 (FC), NIH P01 CA111412 (JSM, SC, DJD, DJW), NIH P01 CA65493 (JSM, SC, JEW, BRB, CB), and NIH R35 197292 (JSM and SC), R01 HL56067, and R37 AI34495 (BRB). FC is an Amy Strelzer Manasevit Research Program Scholar and is supported by a National Marrow Donor Program Award (CON000000052310). DJD and FC are partially supported by AI103960, and DJD is partially supported by CA181045 and CA077544. Research reported in this publication includes work performed in the Analytical Microscopy Core supported by the National Cancer Institute of the NIH under award number P30 CA033572. The content is solely the responsibility of the authors and does not necessarily represent the official views of the NIH.

Address correspondence to: Jeffrey S. Miller, University of Minnesota, 420 Delaware Street SE, Minneapolis, Minnesota 55455, USA. Phone: 612.625.7409; Email: mille011@umn.edu.

1. Hercend T, et al. Characterization of natural killer cells with antileukemia activity following allogeneic bone marrow transplantation. Blood. 1986;67(3):722-728.

2. Savani BN, et al. Rapid natural killer cell recovery determines outcome after T-cell-depleted HLA-identical stem cell transplantation in patients with myeloid leukemias but not with acute lymphoblastic leukemia. Leukemia. 2007;21(10):2145-2152

3. Bergerson RJ, et al. Fewer Circulating Natural Killer Cells 28 Days After Double Cord Blood Transplantation Predicts Inferior Survival and IL-15 Response. Blood Adv. 2016;1(3):208-218.

4. Foley B, et al. Cytomegalovirus reactivation after allogeneic transplantation promotes a lasting increase in educated NKG2C+ 
natural killer cells with potent function. Blood. 2012;119(11):2665-2674.

5. Arase H, Mocarski ES, Campbell AE, Hill AB, Lanier LL. Direct recognition of cytomegalovirus by activating and inhibitory NK cell receptors. Science. 2002;296(5571):1323-1326.

6. Smith HR, et al. Recognition of a virus-encoded ligand by a natural killer cell activation receptor. Proc Natl Acad Sci USA. 2002;99(13):8826-8831.

7. Sun JC, Beilke JN, Lanier LL. Adaptive immune features of natural killer cells. Nature. 2009;457(7229):557-561.

8. Elmaagacli AH, et al. Early human cytomegalovirus replication after transplantation is associated with a decreased relapse risk: evidence for a putative virus-versus-leukemia effect in acute myeloid leukemia patients. Blood. 2011;118(5):1402-1412.

9. Ito S, et al. CMV reactivation is associated with a lower incidence of relapse after allo-SCT for CML. Bone Marrow Transplant. 2013;48(10):1313-1316.

10. Green ML, et al. CMV reactivation after allogeneic HCT and relapse risk: evidence for early protection in acute myeloid leukemia. Blood. 2013;122(7):1316-1324.

11. Cichocki F, et al. CD56dimCD57+NKG2C+ NK cell expansion is associated with reduced leukemia relapse after reduced intensity HCT. Leukemia. 2016;30(2):456-463.

12. Takenaka K, et al. Cytomegalovirus Reactivation after Allogeneic Hematopoietic Stem Cell Transplantation is Associated with a Reduced Risk of Relapse in Patients with Acute Myeloid Leukemia Who Survived to Day 100 after Transplantation: The Japan Society for Hematopoietic Cell Transplantation Transplantation-related Complication Working Group. Biol Blood Marrow Transplant. 2015;21(11):2008-2016.

13. Yoon $\mathrm{JH}$, et al. Impact of cytomegalovirus reactivation on relapse and survival in patients with acute leukemia who received allogeneic hematopoietic stem cell transplantation in first remission. Oncotarget. 2016;7(13):17230-17241.

14. Bao X, et al. Cytomegalovirus induces strong antileukemic effect in acute myeloid leukemia patients following sibling HSCT without ATG-containing regimen. Am J Transl Res. 2016;8(2):653-661.

15. Inagaki J, Noguchi M, Kurauchi K, Tanioka S, Fukano R, Okamura J. Effect of Cytomegalovirus Reactivation on Relapse after Allogeneic Hematopoietic Stem Cell Transplantation in Pediatric Acute Leukemia. Biol Blood Marrow Transplant. 2016;22(2):300-306.

16. Hilal T, Slone S, Peterson S, Bodine C, Gul Z. Cytomegalovirus reactivation is associated with a lower rate of early relapse in myeloid malignancies independent of in-vivo T cell depletion strategy. Leuk Res. 2017;57:37-44.

17. Peric Z, et al. Early human cytomegalovirus reactivation is associated with lower incidence of relapse of myeloproliferative disorders after allogeneic hematopoietic stem cell transplantation. Bone Marrow Transplant. 2018;53(11):1450-1456

18. Teira $\mathrm{P}$, et al. Early cytomegalovirus reactivation remains associated with increased transplant-related mortality in the current era: a CIBMTR analysis. Blood. 2016;127(20):2427-2438.

19. Ramanathan M, et al. Impact of early CMV reactivation in cord blood stem cell recipients in the current era. Bone Marrow Transplant. 2016;51(8):1113-1120.

20. Busca A, et al. The use of ATG abrogates the antileukemic effect of cytomegalovirus reactivation in patients with acute myeloid leukemia receiving grafts from unrelated donors. Am J Hematol. 2015;90(6):E117-E121.

21. Nabekura T, Lanier LL. Tracking the fate of antigen-specific versus cytokine-activated natural killer cells after cytomegalovirus infection. J Exp Med. 2016;213(12):2745-2758.

22. Schlums H, et al. Cytomegalovirus infection drives adaptive epigenetic diversification of NK cells with altered signaling and effector function. Immunity. 2015;42(3):443-456.

23. Lee J, et al. Epigenetic modification and antibody-dependent expansion of memory-like NK cells in human cytomegalovirus-infected individuals. Immunity. 2015;42(3):431-442.

24. Weisdorf DJ. Reduced-intensity versus myeloablative allogeneic transplantation. Hematol Oncol Stem Cell Ther. 2017;10(4):321-326.

25. Morecki S, et al. Immune reconstitution following allogeneic stem cell transplantation in recipients conditioned by low intensity vs myeloablative regimen. Bone Marrow Transplant. 2001;28(3):243-249.

26. Maris M, et al. Immunologic recovery after hematopoietic cell transplantation with nonmyeloablative conditioning. Exp Hematol. 2003;31(10):941-952.

27. Petersen SL, et al. A comparison of T-, B- and NK-cell reconstitution following conventional or nonmyeloablative conditioning and transplantation with bone marrow or peripheral blood stem cells from human leucocyte antigen identical sibling donors. Bone Marrow Transplant. 2003;32(1):65-72.

28. Sanchez-Guijo FM, et al. Long-term immune recovery of patients undergoing allogeneic stem cell transplantation: a comparison with their respective sibling donors. Biol Blood Marrow Transplant. 2005;11(5):354-361.

29. Pagès F, et al. Effector memory T cells, early metastasis, and survival in colorectal cancer. NEngl J Med. 2005;353(25):2654-2666.

30. Wagner JE, et al. One-unit versus two-unit cord-blood transplantation for hematologic cancers. $N$ Engl J Med. 2014;371(18):1685-1694.

31. Appay V, et al. HIV-specific CD8(+) T cells produce antiviral cytokines but are impaired in cytolytic function. $J$ Exp Med. 2000;192(1):63-75.

32. Gamadia LE, et al. Differentiation of cytomegalovirus-specific CD8(+) T cells in healthy and immunosuppressed virus carriers Blood. 2001;98(3):754-761.

33. Zhang T, Scott JM, Hwang I, Kim S. Cutting edge: antibody-dependent memory-like NK cells distinguished by FcR $\gamma$ deficiency. J Immunol. 2013;190(4):1402-1406.

34. Wu Z, et al. Human cytomegalovirus-induced NKG2C(hi) CD57(hi) natural killer cells are effectors dependent on humoral antiviral immunity. J Virol. 2013;87(13):7717-7725.

35. Corat MA, et al. Acquired somatic mutations in PNH reveal long-term maintenance of adaptive NK cells independent of HSPCs. Blood. 2017;129(14):1940-1946.

36. Schlums H, et al. Adaptive NK cells can persist in patients with GATA2 mutation depleted of stem and progenitor cells. Blood. 2017;129(14):1927-1939.

37. Douek DC, et al. Assessment of thymic output in adults after haematopoietic stem-cell transplantation and prediction of T-cell reconstitution. Lancet. 2000;355(9218):1875-1881. 
38. Kelly RM, et al. Short-term inhibition of p53 combined with keratinocyte growth factor improves thymic epithelial cell recovery and enhances T-cell reconstitution after murine bone marrow transplantation. Blood. 2010;115(5):1088-1097.

39. Donahue RE, et al. Discordance in lymphoid tissue recovery following stem cell transplantation in rhesus macaques: an in vivo imaging study. Blood. 2015;126(24):2632-2641.

40. Bradley T, et al. RAB11FIP5 Expression and Altered Natural Killer Cell Function Are Associated with Induction of HIV Broadly Neutralizing Antibody Responses. Cell. 2018;175(2):387-399.e17.

41. Hammer Q, et al. Peptide-specific recognition of human cytomegalovirus strains controls adaptive natural killer cells. Nat Immunol. 2018;19(5):453-463.

42. Cooley S, et al. Donor selection for natural killer cell receptor genes leads to superior survival after unrelated transplantation for acute myelogenous leukemia. Blood. 2010;116(14):2411-2419.

43. Brunstein CG, et al. Umbilical cord blood transplantation after nonmyeloablative conditioning: impact on transplantation outcomes in 110 adults with hematologic disease. Blood. 2007;110(8):3064-3070.

44. O'Connor CM, Murphy EA. A myeloid progenitor cell line capable of supporting human cytomegalovirus latency and reactivation, resulting in infectious progeny. $J$ Virol. 2012;86(18):9854-9865

45. Wussow F, et al. Human cytomegalovirus vaccine based on the envelope gH/gL pentamer complex. PLoS Pathog. 2014;10(11):e1004524

46. Chiuppesi F, et al. Vaccine-Derived Neutralizing Antibodies to the Human Cytomegalovirus gH/gL Pentamer Potently Block Primary Cytotrophoblast Infection. J Virol. 2015;89(23):11884-11898.

47. Andreoni M, Faircloth M, Vugler L, Britt WJ. A rapid microneutralization assay for the measurement of neutralizing antibody reactive with human cytomegalovirus. J Virol Methods. 1989;23(2):157-167.

48. Zhang MJ, Fine J. Summarizing differences in cumulative incidence functions. Stat Med. 2008;27(24):4939-4949. 